\title{
Endothelial Dysfunction in Patients with Obstructive Sleep Apnea (OSA)
}

\section{Duong-Quy $\mathbf{S}^{*}$}

Cardiology - Respiratory Department, Cochin Hospital, Paris Descartes University, Paris

*Corresponding author: Duong-Quy S, Cardiology - Respiratory Department, Cochin Hospital, Paris Descartes University, Paris, Tel: +33.679193377; E-mail: sduongquy.jfvp@gmail.com

Rec date: Jan 12, 2015; Acc date: Jan 13, 2014; Pub date: Jan 15, 2014

Copyright: () 2015 Duong-Quy S. This is an open-access article distributed under the terms of the Creative Commons Attribution License, which permits unrestricted use, distribution, and reproduction in any medium, provided the original author and source are credited.

Keywords: Sleep apnea; Obstructive sleep apnea; Endothelial may be a relevant biomarker of endothelial dysfunction in patients dysfunction; CPAP with OSA.

\section{Introduction}

In cardiovascular system, endothelium has a crucial role for maintaining normal vascular structure and function. For vascular structure, endothelium plays as a barrier at the interface between the blood and tissue. It limits the entry of plasma, molecules, and cells from systemic circulation into tissue. Generally, endothelial dysfunction refers a loss of normal homeostatic functions of blood vessels. It is characterized by unbalance of vasodilation vasoconstriction tonus and disorders of chronic prothrombotic and vascular inflammatory activity, leading to arterial wall damage. Hence, endothelial dysfunction is a marker of vascular abnormality for atherosclerosis formation [1]. Moreover, endothelial dysfunction is also involved in early stage of vascular structural changes due to metabolism or cardiovascular disorders such as dyslipidemia, diabetes or systemic hypertension.

Obstructive sleep apnea (OSA) syndrome, disease with high prevalence in general population, is recognized as a risk factor for both metabolism and cardiovascular disorders [2]. Previous study demonstrated that endothelial dysfunction has been present in patients with OSA syndrome, suggesting it might be a potential mechanism by which OSA develop cardiovascular events and atherosclerosis [3]. In patients with OSA, alterations of structure and elastic property of arterial wall have been reported $[4,5]$. There was an increase of arterial intima thickness and the formation of atheromatous plaques in these patients. Interestingly, arterial stiffness and atherosclerotic volume were significant correlated with the severity of oxygen desaturation and apnea-hypopnea index (AHI). Studying on endothelial structural damage showed that OSA patients have a high density of circulating apoptotic endothelial cells than healthy subjects [6]. Although its specificity has been questioned, circulating apoptotic endothelial cells might be a biomarker for predicting subclinical atherosclerosis and cardiovascular risk. Recently, measurement of level of bone marrow-derived endothelial progenitor cells has been proposed to detect cardiovascular risk in patients with OSA [7].

In addition, patients with OSA have a significant alteration of endothelium-dependent relaxation, confirming by measuring flowmediated dilatation after administration of acetylcholine [8]. Acetylcholine is an endothelium-dependent vasodilator increasing nitric oxide (NO) production via endothelial nitric oxide synthase (eNOS). Other cause involved in endothelial dysfunction in OSA patients is a decrease of NO bioactivity, as observed in active smokers [9]. NO and its derivatives (nitrate and nitrite, NOx) are significantly lower in OSA patients compared with healthy subjects. Therefore, measuring of metabolized products of NO/NOS signaling pathway
To explain the mechanism of endothelial dysfunction in OSA patients, increasing evidences suggest the potential role of intermittent hypoxia during sleep in these patients. In fact, oxygen desaturation indices have been strongly associated with a decrease of endotheliumdependent vasodilation in OSA patients. Intermittent oxygen desaturation is also a cause of oxidative stress involving the alteration of vascular reactivity observed in these patients [10]. Currently, OSA is considered as a systemic inflammation event associated with alterations of adipokine levels, hypercoagulability state, and thrombotic activity. These phenomenons contribute to the development and progression of endothelial dysfunction in OSA patients. In addition, sleep fragmentation due to OSA also contributes to endothelial dysfunction in OSA patients. However, the mechanism of this event remains to be demonstrated.

For physicians working with OSA patients, study on endothelial dysfunction may help to persuade the patients receiving optimal treatment to prevent cardiovascular risk from this disease. Fortunately, treatment with CPAP (continuous positive airway pressure) and its alternative treatment such as mandibular advancement devices, may improve endothelial dysfunction in OSA patients.

\section{References}

1. Yang Z, Ming XF (2006) Recent advances in understanding endothelial dysfunction in atherosclerosis. Clin Med Res 4: 53-65.

2. Nieto FJ, Herrington DM, Redline S, Benjamin EJ, Robbins JA (2004) Sleep apnea and markers of vascular endothelial function in a large community sample of older adults. Am J Respir Crit Care Med 169: 354-360.

3. Simon A, Megnien JL, Chironi G (2010) The value of carotid intimamedia thickness for predicting cardiovascular risk. Arterioscler Thromb Vasc Biol 30: 182-185.

4. Jelic S, Bartels MN, Mateika JH, Ngai P, DeMeersman RE, et al. (2002) Arterial stiffness increases during obstructive sleep apneas. Sleep 25: 850-855.

5. Drager LF, Diegues-Silva L, Diniz PM, Bortolotto LA, Pedrosa RP, et al. (2010) Obstructive sleep apnea, masked hypertension, and arterial stiffness in men. Am J Hypertens 23: 249-254.

6. El Solh AA, Akinnusi ME, Baddoura FH, Mankowski CR (2007) Endothelial cell apoptosis in obstructive sleep apnea: a link to endothelial dysfunction. Am J Respir Crit Care Med 175: 1186-1191.

7. Almendros I, Carreras A, Montserrat JM, Gozal D, Navajas D, et al. (2012) Potential role of adult stem cells in obstructive sleep apnea. Front Neurol 3: 112.

8. Lattimore JL, Wilcox I, Skilton M, Langenfeld M, Celermajer DS (2006) Treatment of obstructive sleep apnoea leads to improved microvascular endothelial function in the systemic circulation. Thorax 61: 491-495.

9. Duong-Quy S (2013) Chronic Smoking and Vascular Disease: What Can we Hope for the Future? J Vasc Med Surg 1: 113. 
Citation: Duong-Quy S (2015) Endothelial Dysfunction in Patients with Obstructive Sleep Apnea (OSA). J Vasc Med Surg 3: e116. doi: 10.4172/2329-6925.1000e116

Page 2 of 2

10. Jurado-Gámez B, Fernandez-Marin MC, Gómez-Chaparro JL, MuñozCabrera L, Lopez-Barea J, et al. (2011) Relationship of oxidative stress and endothelial dysfunction in sleep apnoea. Eur Respir J 37: 873-879. 